\title{
How training is encouraging mothers to deliver in health facilities in Ulang, South Sudan
}

\author{
Panom Puok Duoth Kier \\ Health Manager for SSAID/County Health \\ Coordinator
}

Correspondence:

Panom Puok Duoth Kier

panompuokduoth@gmail.com

Submitted: July 2021

Accepted: September 2021

Published: November 2021
Citation: Kier. How training is encouraging mothers to deliver in health facilities in Ulang, South Sudan. South Sudan Medical Journal 2021;14(4):135137 (C) 2021 The Author (s) License: This is an open access article under CC BY-NC DOI: https://dx.doi.org/10.4314/ssmj. v14i4.7

\section{Abstract}

In South Sudan, health facility delivery coverage is very low despite the presence of health facilities with staff that can conduct deliveries. Some factors like inaccessibility, insecurity, low knowledge of benefits of health facility delivery, poor services, financial challenges, family influence and cultural practices might be some of the reasons that prevent some mothers from delivering in the health facilities.

This paper describes how UNICEF with other partners has started training master trainers with Basic Emergency Obstetrics and New Born Care modules in Greater Upper Nile, and includes a case of one mother who benefited from the training.

Key words: Obstetric training, newborn training, delivering in health facilities, Ulang, South Sudan

\section{Introduction}

South Sudan continues to be among the top countries with a high Maternal Mortality Ratio (MMR) and Newborn Mortality Rate (NMR). These were estimated at 800 per 100,000 live births and 39 per 1000 live births respectively according to a study conducted in 2015. ${ }^{[1]}$ One reason for these poor rates is that, in South Sudan, health facility delivery coverage is very low even though there are health facilities with skilled health workers who can attend mothers during labour and birth. ${ }^{[2]}$

Despite the tremendous efforts geared toward improving facility delivery, mothers continue to deliver at home for a variety of reasons such as: inaccessibility to health facilities due to distance and insecurity, low knowledge of the benefits of health facility delivery, poor services, financial challenges, family influence, and cultural practices.

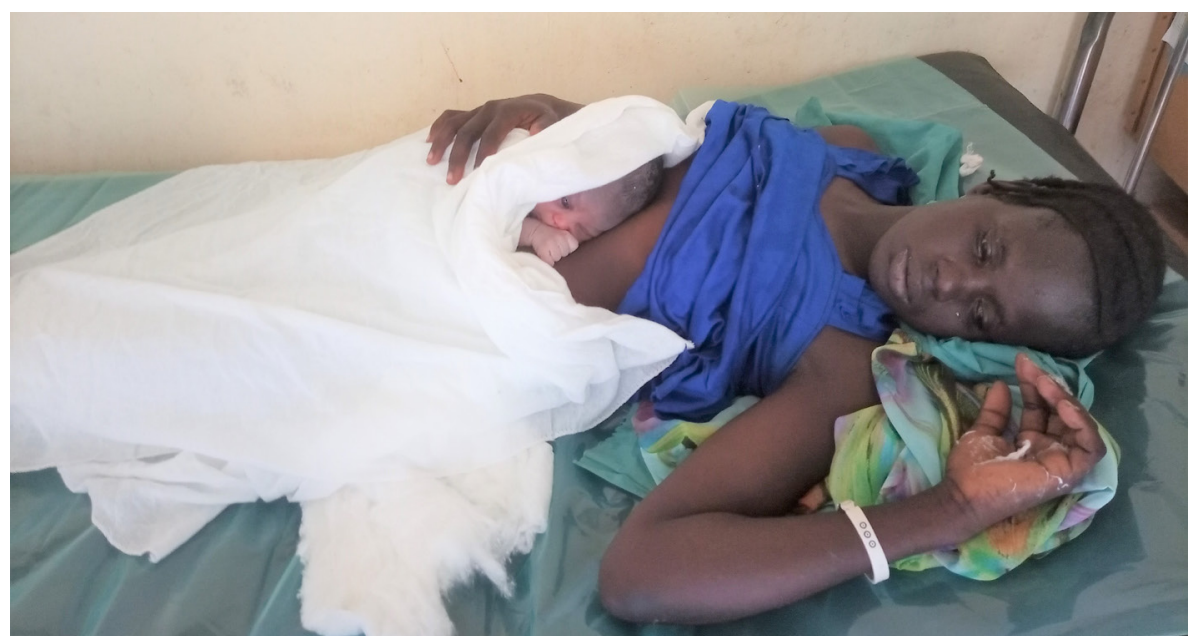

Figure 1. Nyakoang Puok Padoch with her newborn baby enjoying skin to skin care within one hour after delivery at Yomding PHCC (photo taken with Nyakoang's permission). 


\section{Box 1. The training modules}

Provision of Basic Emergency Maternal Obstetric and Newborn Care (BeMONC) is a critical element in improving the health outcomes of pregnant women and newborns. To achieve this; building the capacity of health workers to deliver high quality health services is a key element under the WHO pillars of health systems strengthening.

Helping Mothers Survive (HMS) and Helping Babies Survive (HBS) modules build the capacity of all providers to give compassionate, routine and lifesaving care to women and babies; care that honours women's choices. These training modules are designed to be delivered at the job site to the entire team of providers involved in the care of women and their families. These teams include skilled birth attendants such as midwives, doctors and other team members like nurses and support staff. There are a total of 8 modules which are being delivered in phases of two modules per each training.

Up to date, the 4 modules that have been covered in Ulang are:

- Essential Care during Labor and Birth

- Essential Care for Every Baby

- Helping Babies Breathe and

- $\quad$ Bleeding after Birth Complete.

According to the 2010 South Sudan Household and Demographic Survey report, health facility delivery attended by a skilled birth attendant was estimated to be around only $12 \%$. $^{[3]}$

\section{Training front-line health workers}

To support Primary Health Care services in Greater Upper Nile mainly in Jonglei and Upper Nile States, the World Bank, through UNICEF, issued a grant for 20 months (from July 1, 2019 to February 28, 2021) to the health implementing partners operating in these two States. This was to support health services, including maternal and child health services and so decrease maternal and newborn mortality.

Therefore, to improve the knowledge and skills of frontline health workers especially midwives and all those who are directly or indirectly involved in conducting deliveries, UNICEF with other partners like the National Ministry of Health and Johns Hopkins Program for International Education in Gynaecology and Obstetrics (JHPIEGO) started training master trainers with Basic Emergency Obstetrics and New Born Care modules (See Box 1 for details). ${ }^{[4,5,6,7]}$ This training used a Low Dose High Frequency approach by which the training could be cascaded from master trainers down to the health facility staff at various groups across Jonglei and Upper Nile States.

Due to the knowledge and skills gained through this training, it is thought that a number of delivery-related potentially fatal complications were successfully managed by the trainers and the staff they have trained. Also, more women are being encouraged to deliver in a health facility as the story below illustrates.

\section{The story of Madam Nyakoang Puok Padoch}

I, Panom Puok Duoth Kier, am among the master trainers who have benefited from this training. Here I share my experience when I interacted with one mother who came for delivery at Yomding PHCC when I was there to conduct the Helping Babies Breath (HBB) module training.

This story illustrates that some women do want to deliver in health facilities in spite of challenges such as difficult journeys, and that, if they get good care, they can be advocates to others to do the same - just as Nyakoang Puok Padoch has done.

It was just around 9 am on June 17, 2021 when Nyakoang Puok Padoch was rushed to Yomding PHCC while in labour pain.

Nyakoang Puok Padoch, aged 28 years, Gravida 5, Para 4, had attended the antenatal clinic (ANC) at Yomding PHCC three times during this pregnancy. She had been attending ANC during all her previous pregnancies.

Nyakoang lives in the village of Tuaregany across the river from Yomding, a distance of approximately five kilometers; there is no health facility in the village so villagers have to come to Yomding for health services.

According to Nyakoang her labour pains started at $5 \mathrm{pm}$ on June 16 when she was working on her farm but she was unable to reach Yomding until the next day as there was no canoe that could take her across the river. She had to wait all night in labour until she could reach the Yomding PHCC the next morning. There, at exactly at 9:39 am, Nyakoang delivered, with care from myself and the midwives I was training, a healthy baby boy who was 


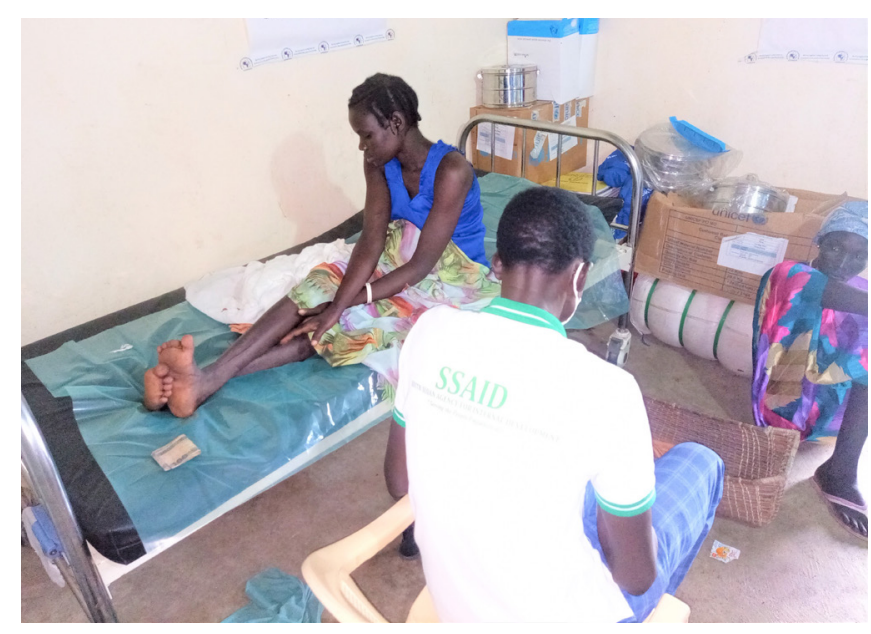

Figure 2. Panom Puok Duoth (Health Manager for SSAID/County Health Coordinator for Lot 5) interviewing Madam Nyakoang Puok Padoch and her caretaker on the importance of health facility delivery at Yomding PHCC (Photo taken with Nyakoang's permission).

crying, breathing well and responding to touch within the first minute after birth. All the necessary care, including skin-to-skin care (Figure 1) was provided to Nyakoang and the newborn as soon as the baby was delivered. Later I interviewed her about the care she had received and what she felt about delivering in a health facility (Figure 2).

Nyakoang, said, "Delivery in a health facility is very important; when I came here, I was suffering but after I delivered, I felt well", and, "I am very happy with the midwives (Thichiot Lim, Gnajuok Panom and Mama Nyaleek Tong) at Yomding PHCC who have assisted me when I was delivering."

Nyakoang's message to other mothers is, "I tell every mother to come and deliver in the health facility. It is the safest place to have your baby and they will help you if you have complications."

\section{References}

1. Sami S, Kerber K, Kenyi S, et al. State of newborn care in South Sudan's displacement camps: A descriptive study of facility-based deliveries. Reprod. Health 2017, 14, 161. https:// reproductive-health-journal.biomedcentral.com/ articles/10.1186/s12978-017-0417-z

2. Alkema L, Chou D, Hogan D, et al. Global, regional, and national levels and trends in maternal mortality between 1990 and 2015, with scenario-based projections to 2030: A systematic analysis by the UN Maternal Mortality Estimation Inter-Agency Group. Lancet 2016, 387, 462474. https://www.thelancet.com/journals/lancet/ article/PIIS0140-6736(15)00838-7/fulltext

3. The Republic of South Sudan: The Sudan Household Health Survey 2010. https://reliefweb. int/report/south-sudan-republic/republic-southsudan-sudan-household-health-survey-2010

4. Helping Mothers Survive. Essential care for Labor and Birth https://hms.jhpiego.org/essential-carelabor-and-birth/

5. Helping Babies Survive. Essential Care for Every Baby https://www.aap.org/en-us/advocacy-andpolicy/aap-health-initiatives/helping-babiessurvive/Pages/Essential-Care-Every-Baby.aspx

6. Helping Babies Survive. Helping Babies Breathe https://www.aap.org/en-us/advocacy-and-policy/ aap-health-initiatives/helping-babies-survive/ Pages/Helping-Babies-Breathe.aspx

7. Helping Mothers Survive. Bleeding after Birth Complete https://hms.jhpiego.org/bleeding-afterbirth-complete/ 